\title{
13
}

\section{THE EVOLUTIONARY ARgUMENT FOR ATHEISM}

\author{
Daniel Howard-Snyder
}

It is commonly said that Darwinian evolution conflicts with theistic religion. Those who say such things often have in mind claims that are peripheral to theistic religion, for example, the claim that God created the earth about 6,000 years ago or the claim that God directly created each species. I have no interest in the thesis that Darwinian evolution conflicts with these peripheral claims. I do have an interest, however, in the thesis that Darwinian evolution conflicts with claims that are central to theistic religion. Among those who say that Darwinian evolution conflicts with claims central to theistic religion, we find those who say that it is incompatible with them and those who say that, although there is no incompatibility, evolution nevertheless provides significant evidence against them. In this essay, I will focus on the second group. ${ }^{1}$ More narrowly, I will focus on Paul Draper's argument for this conclusion. ${ }^{2}$

\section{DRAPER'S EVOLUTIONARY ARGUMENT FOR ATHEISM}

Draper characterizes evolution as consisting of two theses:

Evolution. (1) The genealogical thesis: All complex organisms are the more or less gradually modified descendants of a small number of simple unicellular organisms.

(2) The genetic thesis: All evolutionary change in populations of complex organisms either is or is the result of trans-generational genetic change. ${ }^{3}$

Notice that evolution, so understood, is silent about the mechanisms of evolutionary change. Darwinism is not silent. According to Darwinism, says Draper,

\footnotetext{
${ }^{1}$ For an extensive discussion of a variety of incompatibility claims, see van Inwagen 2010.

2 Draper 2008a [1997].

3 Ibid., 209.
} 
Darwinism. Natural selection operating on random genetic mutation is the principal mechanism driving evolutionary change. ${ }^{4}$

Darwinian evolution is the conjunction of Darwinism and evolution.

Draper asserts that evolutionary arguments for atheism that "appeal to Darwinian evolution rather than just to evolution...overestimate the strength of the evidence for Darwinism". ${ }^{5}$ Draper does not say why he thinks that this is so, but for our purposes it does not matter. What matters is that he appeals only to evolution, the evidence for which, he says, "is overwhelming-so overwhelming that evolution can legitimately be taken as fact rather than mere theory". Draper has in mind the evidence one finds in biology textbooks: "information about selective breeding and other changes within populations of animals, as well as what we know about the geographical distribution of living things, homologies, the fossil record, genetic and biochemical evidence, imperfect adaptations, and vestigial organs". 6

I'm not so sure that the textbook evidence allows us to regard evolution, as Draper defines it, as "fact rather than mere theory". That's because I'm not so sure about whether the textbook evidence suffices for us to say that it is a fact that all complex organisms are the more or less gradually modified descendents of a small number of simple unicellular organisms. In this connection, we might consider those theorists who in their theorizing seem to stretch the meaning of "more or less gradual modification" to the breaking point. For example, do the products of the flurries of adaptations within a population followed by long-term stability postulated by Eldredge and Gould in their theory of punctuated equilibria still count as gradually modified descendents of their predecessors? Or what about the distinct populations that suddenly appear in the fossil record near the beginning of the Cambrian period? Are they the more or less gradually modified descendents of their predecessors, even on a geological time scale? Or consider the sort of change postulated by many anthropologists and biolinguists in relation to human evolution. The fossil record, some of them say, strongly suggests that anatomically modern humans, who were behaviorally indistinguishable from their primitive neighbors, the Neanderthals and homo erectus, gained the suite of cognitive capacities typical of behaviorally modern humans,

\footnotetext{
${ }^{4}$ op cit.

${ }^{5}$ op cit.

${ }^{6}$ op cit.
} 
including the capacity for language, virtually "instantaneously". ' Here are Noam Chomsky's speculations about the matter:

An elementary fact about the language faculty is that it is a system of discrete infinity. Any such system is based on a primitive operation that takes $n$ objects already constructed, and constructs from them a new object: in the simplest case, the set of these $n$ objects. Call that operation Merge. Either Merge or some equivalent is a minimal requirement [for the possession of language]. With Merge available, we instantly have an unbounded system of hierarchically structured expressions. The simplest account of the "Great Leap Forward" in the evolution of humans would be that the brain was rewired, perhaps by some slight mutation, to provide the operation Merge, at once laying a core part of the basis for what is found at that dramatic "moment" of human evolution, at least in principle; to connect the dots is no trivial problem. There are speculations about the evolution of language that postulate a far more complex process: first some mutation that permits two-unit expressions (yielding selection advantage in overcoming memory restrictions on lexical explosion), then mutations permitting larger expressions, and finally the Great Leap that yields Merge. Perhaps the earlier steps really took place, but a more parsimonious speculation is that they did not, and that the Great Leap was effectively instantaneous, in a single individual, who was instantly endowed with intellectual capacities far superior to those of others, transmitted to offspring and coming to predominate, perhaps linked as a secondary process to the [sensori-motor] system for externalization and interaction, including communication as a special case. At best a reasonable guess, as are all speculations about such matters, but about the simplest one imaginable, and not inconsistent with anything known or plausibly surmised. In fact, it is hard to see what account of human evolution would not assume at least this much, in one or another form. ${ }^{8}$

If I understand him correctly, Chomsky speculates here that the transition from wholly lacking to fully possessing the capacity to think with "an unbounded system of hierarchically

\footnotetext{
${ }^{7}$ Diamond 1992.

${ }^{8}$ Chomsky 2005: 11-12.
} 
structured expressions," and all that that entails, "was effectively instantaneous, in a single individual, who was instantly endowed with intellectual capacities far superior to those of others," shortly thereafter "linked" in offspring "as a secondary process to the [sensorimotor] system for," among other things, communication. He seems to be suggesting that the individual in question was virtually capable of thinking in a language, but its parents were not. Put the parents, as infants, in a modern English-speaking home, and they'd never learn to think in English. But their child would, as would their grandchildren, great-grandchildren, and so on. Indeed, he seems to suggest that their child, raised in an English-speaking home, would have been able to speak English too if the evolution of her sensori-motor system had kept apace with a similarly serendipitous "slight mutation" producing the requisite cerebral "rewiring".

Like I said, I am unsure about whether the organisms resulting from these sorts of postulated adaptations count as the more or less gradually modified descendents of their predecessors. I would imagine, however, that those who postulate such things are well aware of the textbook evidence Draper mentions. Will they regard their postulations as conflicting with that evidence? I doubt it. Still, I think we can safely say that they mean to push the semantic boundaries of "more or less gradually modified," especially "less". That's one reason why their "more" gradualist colleagues raise a ruckus about their postulations. (Witness the highly publicized row between Dawkins and Gould, for example.) Of course, we can easily imagine some maverick graduate students really pushing the boundaries. That's what grad students do. To be sure, there is no sharp line between "more or less gradual" and "not gradual". Nevertheless, among the possible pathways of genetic space there exist many a "great leap" from one point to another where, were they able, the keepers of the guild would look at the offspring, and then back at its parents, and rightly say: "the postulated mutation and subsequent adaptation is just too quick for that offspring to be a more or less gradually modified descendent of theirs". Were such a situation to arise, would the keepers of the guild be able to correct the mavericks by pointing to uncontroversial "information about selective breeding and other changes within populations of animals, as well as what we know about the geographical distribution of living things, homologies, the fossil record, genetic and biochemical evidence, imperfect adaptations, and vestigial organs”?

\footnotetext{
9 Of course, friends of the alternative continuity hypothesis are rather down on the idea that some human's brain could be "rewired" by a "slight mutation" with the result Chomsky envisions. (See Mcbrearty 2000).
} 
I suppose so. After all, the textbook evidence is impressive, to say the least. Still, I'm not sure, and I'm unsure enough to refrain from joining Draper in his unsurpassably high opinion of the textbook evidence. Nevertheless, let's grant his opinion and move on.

So then: how does Draper propose to move from the fact of evolution to atheism? At the most general level, he argues that, antecedently, evolution is much more probable on the assumption that naturalism is true than on the assumption that theism is true; thus, since naturalism entails the denial of theism and naturalism is no less intrinsically probable than theism, theism is very probably false-all other evidence held equal. It will prove useful to state Draper's argument explicitly.

1. Evolution is true.

2. Antecedently, evolution is much more probable on naturalism than on theism.

3. Naturalism is no less intrinsically probable than theism.

4. So, all other evidence held equal, naturalism is much more probable than theism. $(1-3)$

5. Naturalism entails the denial of theism.

6. So, all other evidence held equal, theism is very probably false. $(4,5)$

Before we assess Draper's defense of his argument, we must get clearer on its central terms.

\section{DEFINITIONS}

When he originally published his argument, Draper defined naturalism as the thesis that "the physical universe is a 'closed system' in the sense that nothing that is neither a part nor a product of it can affect it". ${ }^{10}$ This is an inadequate definition of naturalism. For consider the view that concrete reality, as opposed to abstract reality, is exhausted by two realms, one material and one immaterial. Immaterial souls populate the immaterial realm, one of whom is a perfect personal God. But since, on the view in question, it is a matter of metaphysical necessity that there is no causal interaction between these two realms, God cannot affect the material realm; nor can lesser souls. On Draper's definition, this view is a version of naturalism. That is the wrong result.

${ }^{10}$ Draper 2008a [1997]: 208. 
Draper more recently defined naturalism by first defining "physical entities" and "natural entities". Physical entities, he says, are "entities of the sort studied in the physical sciences (e.g. atoms) along with any other as yet undiscovered entities whose behavior is governed by the fundamental laws of physics". ${ }^{11}$ Natural entities, he says, are "physical entities and entities that are either ontologically reducible to physical entities or are caused by physical entities". ${ }^{12}$ Given these definitions, Draper defines naturalism as the thesis that there are natural entities and "[they] have only natural causes". ${ }^{13}$ This definition of naturalism is also inadequate. For what counts as "entities of the sort studied in the physical sciences"? I should think that the correct answer is this: whatever sort of entities the practitioners of the physical sciences might appeal to in their theorizing as scientists. Of course, since some physical scientists, whether past, present, future or merely possible, aim to articulate, or at least contribute to an articulation of, a Final Theory, a Theory of Everything, who's to say what they might appeal to? Moreover, given that what they in fact appeal to is a highly contingent matter, dependent on culture, politics, personalities, incentives, and so forth, who's to say that they could not appeal to God, or something sufficiently like him? Is that really so far-fetched? I don't think so. Many scientists are willing to posit the non-existence of God while doing their science. Why might not some of them find it useful someday to return the favor? Surely that's possible. So, by Draper's definition, a personal God qualifies as a physical entity, and so a natural entity, and so not a supernatural entity, and so not ruled out by naturalism. Again, this is the wrong result. (This definition also runs afoul of the worry for the first definition.)

Most recently, Draper distinguishes "the mental world" from "the physical world," that is "the world of conscious experiences like thoughts, feelings, imaginings, and sensations" from "the world of rocks, chemical reactions, galaxies, and neurons," and then says that "[n]aturalists claim that either the mental world does not exist or it does exist but is asymmetrically dependent on the existence of the physical world (i.e., were it not for a physical world, there would be no mental world, while there would still be a physical world even if there were no mental world)". ${ }^{14}$ But again, this is inadequate. For it implies that one is a naturalist if, but not only if, one thinks that there is a mental world and a physical world

11 Draper 2008b: 150.

12 Op. cit.

13 Ibid., 149-150.

${ }^{14}$ Draper 2013: 69-70. 
and, in addition, that (i) if there were no physical world, there would be no mental world and (ii) if there were no mental world, there might still be a physical world. Imagine a theist who holds that God exists necessarily and that it's necessary that God creates a physical world. ${ }^{15}$ Naturally, she will infer that it's necessary both that there's a mental world and a physical world, in which case she will think that the antecedents of (i) and (ii) are absolutely impossible. Further, imagine that she endorses the standard semantics for counterpossibles, according to which every counterpossible is trivially true. Then she will infer that (i) and (ii) are both true. Thus, on Draper's definition, she is a naturalist. But clearly she is not.

Draper is not the first person to face difficulty defining naturalism. In David Papineau's opinion, “[t] he term 'naturalism' has no very precise meaning in contemporary philosophy" and he suggests that "[i]t would be fruitless to try to adjudicate some official way of understanding the term". ${ }^{16}$ Of course, Draper does not need an "official way of understanding the term". He only needs one that both renders premise (5) of his argument true- "Naturalism entails the denial of theism" — and rules out what naturalists unanimously want to rule out, i.e. a personal God and immaterial souls. Draper's definitions do not do that.

I propose that we adopt the well-worn adage that naturalism is the view that there is no God or anything like him. Despite its imprecision, at least it satisfies our two desiderata. As for theism, let's go with Draper's definition: there is a personal God, perfect in power, knowledge, and moral goodness, who is the creator of the physical universe and who can intervene in it. $^{17}$

Draper concludes that evolution makes it very probable or likely that theism is false, all other evidence held equal. But what does he mean by "probable" and "likely"? There are many different ways to understand these terms. ${ }^{18}$ Draper says that by "probable" and "likely" he means epistemic probability. Of course, that's helpful only if we know what that is. In the only published comment on the matter that I know of, Draper says that epistemic probability is poorly understood. He's right. Still, he says that we can get by with the following formulation: "Relative to $\mathrm{K}, \mathrm{p}$ is epistemically more probable than $\mathrm{q}$, where $\mathrm{K}$ is

\footnotetext{
15 Perhaps Aquinas fits this description. See Kretzmann 1998.

16 Papineau 2009).

${ }^{17}$ Draper 2008a [1997]: 207.

${ }^{18}$ For some of those ways, see Hájek 2012.
} 
an epistemic situation and $\mathrm{p}$ and $\mathrm{q}$ are propositions, just in case any fully rational person in $\mathrm{K}$ would have a higher degree of belief in $\mathrm{p}$ than in q". ${ }^{19}$

One difficulty with Draper's formulation is that it presupposes that belief comes in degrees. After all, if belief does not come in degrees, then, given his formulation, there is no such thing as epistemic probability and so nothing bears that relation to anything else, in which case three of the six statements that comprise his evolutionary argument for atheism are false, including the conclusion. So those of us who deny that belief comes in degrees, but who wish to engage that argument, must look elsewhere to gain some purchase on epistemic probability. $^{20}$

Fortunately, we need not look far. For when Draper argues for instances of ' $p$ is more epistemically probable than q given $\mathrm{K}$ ' and the like, he argues for instances of 'we have better reason to believe (or expect) $\mathrm{p}$ than q given $\mathrm{K}$ ' and their kin. In fact, he never argues for instances of the former without arguing through instances of the latter. Of course, those of us who deny that there are degrees of belief are perfectly happy with better and worse reason. For example, I have much better reason to believe that yellow jackets can fly than that hippos can fly; and I have much better reason to expect to see a bald eagle soaring over Whatcom County's Lake Padden in Spring than a penguin waddling along its banks anytime. So in what follows I will understand epistemic probability as follows: given $\mathrm{K}, \mathrm{p}$ is more epistemically probable than $\mathrm{q}$ for someone if and only if, given $\mathrm{K}$, he has better reason to believe or expect $\mathrm{p}$ than $\mathrm{q}$, where $\mathrm{K}$ is his epistemic situation. Thought of in this way, epistemic probability is a measure of the comparative goodness of one's reason to believe $\mathrm{p}$ rather than q, given K. In what follows, I will be so bold as to say that this is Draper's understanding of epistemic probability, even though I have neither heard nor seen him say or write any such thing. ${ }^{21}$

Notice that epistemic probability understood as Draper understands it is relative to a person and her epistemic situation at a time. Consequently, something might be epistemically probable for a person at one time but not for the same person at another time. Furthermore, something might be epistemically probable for one person at one time but not for another person at the same time. This last fact raises a pointed question: just whose epistemic

\footnotetext{
${ }^{19}$ Draper 1989: 349n2; 1996: 27n2.

${ }^{20}$ Cp. van Inwagen 1997:69-70.

${ }^{21}$ For a very different understanding of epistemic probability and its relation to arguments framed in the way Draper frames the argument under discussion, see van Inwagen 1997.
} 
probabilities are in question when Draper frames his evolutionary argument for atheism? In what follows, I will deploy the fiction of epistemic probability being relative to our epistemic situation, and I will speak in terms of what we have reason to believe given our epistemic situation. At one crucial point, however, I will dispense with that fiction and speak only of myself. (This is also as good a place as any to call the reader's attention to the fact that, in much of what follows, I will leave reference to our epistemic situation implicit.)

Draper's understanding of epistemic probability raises several more questions. For example, exactly what is this "epistemic situation" of which he speaks? Does it include nonmental items as well as mental items? If so, which ones? Among the mental items, what does it include and what does it exclude? And what is it to "have" good reason? And what does the goodness of good reason consist in? And what's meant by "reason" anyway? Is it just another word for evidence? If so, which of the alternative conceptions of evidence is intended? And so on. It is clear that Draper relies on the fact that the axioms of probability theory, and certain theorems as well, are true of epistemic probability. I will grant his reliance on these things but, like him, I am not going to answer the questions that remain, although it will be evident enough that I will assume without argument partial answers to some of them at certain points in what follows.

Draper also says things of the form 'Antecedently, $\mathrm{r}$ is more probable on $\mathrm{p}$ than $\mathrm{q}$,' as when he states that, antecedently, evolution is much more probable on naturalism than on theism. By "antecedently" in that statement Draper means "independent of the observations and testimony that together constitute the primary evidence" upon which our knowledge of evolution is based..$^{22}$ Thus, given Draper's understanding of epistemic probability, Draper means that, if we "abstract from" our evidence for evolution, we have much better reason to believe or expect evolution on naturalism than on theism.

It is important for Draper's purposes that what remains after abstraction includes the fact that complex life exists and the fact that at one time there was no life (among other facts). That is because it is no part of Draper's aim to argue that those two facts are more likely on naturalism than on theism. Evolution is his exclusive focus.

As for the comparative intrinsic probability of a pair of incompatible theses, the rough idea is that if we abstract away from all (extrinsic) evidence for and against them, and we simply focus on what they say, we will be able to tell which is more probable on its own (if

22 Draper 2008a [1997]: 209. 
either is); that is, we will be able to tell which we have more reason to believe or expect (if either). The very idea of intrinsic probability is vexing, to say the least. More vexing still is its value for adjudicating incompatible metaphysical theses and how it can be measured without bias. Of course, Draper's argument requires a stance on these issues, a stance that at least some will find problematic. Rather than explore the matter further here, I will quickly pass over premise (3) - the claim that naturalism is at least as intrinsically probable as theismonly pausing long enough to call our attention to the vexation it can arouse. ${ }^{23}$ Nor will I say anything about Draper's inference from (1)-(3) to (4), except that he assumes it is valid given two theorems of the probability calculus that, he says, are true of epistemic probability.

I want to focus on premise (2).

\section{DRAPER'S DEFENSE OF PREMISE 2: AN OVERVIEW}

Here’s premise (2) again:

2. Antecedently, evolution is much more probable on naturalism than on theism.

That is, abstracting from our evidence for evolution, we have much better reason to believe or expect evolution on naturalism than we do on theism. Draper's defense of (2) begins with another definition:

Special creationism. Some complex organisms are not the more or less gradually modified descendants of a small number of simple unicellular organisms, but rather were created by the direct intervention of God in the natural order. ${ }^{24}$

Obviously enough, since evolution includes the genealogical thesis, according to which all complex organisms are the more or less gradually modified descendents of a small number of simple unicellular organisms, "evolution entails that special creationism is false". ${ }^{25}$ In that

${ }^{23}$ I should note that in his 2008a [1997], Draper does not speak in terms of intrinsic probability but rather in terms of plausibility. More recently, however, he describes the comparative plausibility of naturalism and theism in terms of their intrinsic probability. Google 'paul draper intrinsic probability'.

${ }^{24}$ Draper 2008a [1997]: 209.

25 Ibid., 209-210. 
case, says Draper, it follows from some basic theorems of the probability calculus that are true of epistemic probability, that we can "establish" (2) if we establish that

special creationism is antecedently much more [epistemically] likely to be false on naturalism than on theism and that, even on the assumption that special creationism is false, evolution is still antecedently at least as [epistemically] likely to be true on naturalism as it is on theism. ${ }^{26}$

That is, to establish (2), Draper sets out to establish that, when we abstract from our evidence for evolution and reflect on what remains, we will discover two things: (i) we have much better reason to believe the denial of special creationism given naturalism than we have given theism, and (ii) assuming the denial of special creationism, we have at least as good reason to believe evolution given naturalism than we have given theism.

Draper puts these matters more formally. Let 'T,' 'N,' 'E,' and 'S' stand for theism, naturalism, evolution, and special creationism respectively; let ' $>$ !' stand for 'is much greater than'; let ' $\geq$ ' stand for 'is equal to or greater than'; let ' $\leq$ ' stand for 'is equal to or less than'; and let 'P' stand for 'the antecedent epistemic probability of'. (Notice how 'P' buries reference to particular persons in a particular epistemic situation at a particular time.) Since $S$ entails $\sim \mathrm{E}$, says Draper,

$$
\mathrm{P}(\mathrm{E} / \mathrm{N})>! \mathrm{P}(\mathrm{E} / \mathrm{T}) \text { if and only if } \mathrm{P}(\sim \mathrm{S} / \mathrm{N}) \times \mathrm{P}(\mathrm{E} / \sim \mathrm{S} \& \mathrm{~N})>! \mathrm{P}(\sim \mathrm{S} / \mathrm{T}) \times \mathrm{P}(\mathrm{E} / \sim \mathrm{S} \& \mathrm{~T}) \text {. }
$$

To establish that the right hand side of the biconditional is true, it suffices to establish (i) $\mathrm{P}(\sim \mathrm{S} / \mathrm{N})>$ ! $\mathrm{P}(\sim \mathrm{S} / \mathrm{T})$ and (ii) $\mathrm{P}(\mathrm{E} / \sim \mathrm{S} \& \mathrm{~N}) \geq \mathrm{P}(\mathrm{E} / \sim \mathrm{S} \& \mathrm{~T})$. In what follows, I will focus on (i). Before I turn to Draper's defense of (i), it will prove instructive to consider Alvin Plantinga's recent critique of Draper's argument.

\section{PLANTINGA ON DRAPER'S ARGUMENT}

In Where the Conflict Really Lies, Plantinga contends that Draper's argument fails for two reasons.

${ }^{26}$ Ibid., 210. 
First, he says, if theism is noncontingent, "[Draper's] argument won't be relevant". ${ }^{27}$ Plantinga does not identify what it will not be relevant to, but we can gather from the context that he means that it will not be relevant to Draper's overall defense of the claim that naturalism is more likely than theism, all other evidence held equal. He writes:

Suppose...that theism is noncontingent: necessarily true or necessarily false. If so, [Draper's premise 2] doesn't imply that naturalism is more likely than theism; instead [2] obviously entails that theism is true. For if theism is noncontingent and false, then it is necessarily false; the probability of a contingent proposition on a necessary falsehood is 1; hence $\mathrm{P}(\mathrm{E} / \mathrm{T})$ is 1 . But if, as Draper claims, $\mathrm{P}(\mathrm{E} / \mathrm{N})$ is greater than $\mathrm{P}(\mathrm{E} / \mathrm{T})$, then $\mathrm{P}(\mathrm{E} / \mathrm{T})$ is less than 1 , hence $\mathrm{T}$ is not necessarily false. If $\mathrm{T}$ is not necessarily false, however, then (given that it is noncontingent) it is necessarily true. So if theism is noncontingent, and [Draper's premise 2] is true, then theism is true, and indeed necessarily true. ${ }^{28}$

What should we make of these words?

So far as I can see, they contain a misunderstanding. Draper thinks of probability as epistemic probability. Thinking of probability in this way, it is false that "the probability of a contingent proposition on a necessary falsehood is 1". Witness Dmitry. Dmitry thinks

B. Mt. Baker's elevation is 10,781 feet,

which is a contingently true proposition. He also thinks

L. Lying whenever it suits him is morally acceptable,

which is a necessary falsehood. Should we conclude that the epistemic probability for Dmitry of (B) on (L) is 1 ? That is, should we conclude that, given his epistemic situation, he has maximally good reason to believe (B) on (L)? Of course we shouldn't. It appears, therefore, that Plantinga's first objection to Draper's evolutionary argument for atheism

27 Plantinga 2011: 50-51.

28 Ibid., 50. 
misses the mark: it is not true that "the probability of a contingent proposition on a necessary falsehood is $1 "$.

Perhaps there is some other understanding of probability on which "the probability of a contingent proposition on a necessary falsehood is 1". For example, perhaps there is some understanding of probability on which the following argument is sound: for any proposition $\mathrm{p}$ and $\mathrm{q}$, if $\mathrm{p}$ is necessarily false and $\mathrm{q}$ is true, then it's not possible for $\mathrm{p}$ to be true and $\mathrm{q}$ to be false; moreover, for any proposition $\mathrm{p}$ and $\mathrm{q}$, if it's not possible for $\mathrm{p}$ to be true and $\mathrm{q}$ to be false, then the probability of $\mathrm{q}$ on $\mathrm{p}$ is 1 ; so, for any proposition $\mathrm{p}$ and $\mathrm{q}$, if $\mathrm{p}$ is necessarily false and $q$ is true, then the probability of $q$ on $p$ is 1 . Of course, if we think of probability as a measure of the possible worlds at which both $\mathrm{p}$ and $\mathrm{q}$ are true over those at which $\mathrm{p}$ is true, or if we think of it as a measure of the area of logical space at which both $\mathrm{p}$ and $\mathrm{q}$ are true over that at which $\mathrm{p}$ is true, then, since there is no world or region at which $\mathrm{p}$ is true- it is necessarily false, after all—the probability of $\mathrm{q}$ on $\mathrm{p}$ is $0 / 0$ - which is not 1 . So those understandings of probability will not serve Plantinga's purposes. But perhaps he has some other understanding of probability in mind according to which our little argument, or perhaps some other argument with the same conclusion, is sound. Whatever may be the case on that score, it remains clear that on Draper's understanding of epistemic probability, it is false that "the probability of a contingent proposition on a necessary falsehood is 1 ".

Plantinga's second objection seems to miss the mark as well. After summarizing the basic structure of Draper's argument for premise 2, he writes:

Suppose this [that is, premise 2] is true: how much does it really show? As he [Draper] says, if all else is evidentially equal, theism is improbable. But of course all else is not evidentially equal. Aren't there a host of other probabilities in the neighborhood that favor theism at least as heavily? ${ }^{29}$

He then cites the probability of there being life on earth given theism, and the probability of there being intelligent beings, and beings with a moral sense, and creatures who worship God. He continues:

\footnotetext{
${ }^{29}$ Ibid., 51.
} 
There will also be other "known facts" that are more probable on theism than on naturalism. If so, however, the evidence favoring naturalism over theism that Draper cites will be more than counterbalanced by evidence favoring theism over naturalism. ${ }^{30}$

Of course, Draper never denied any of this; in fact, he explicitly acknowledged it. That was the point of the "all other evidence held equal" qualification. Draper's sole concern is the evidential status of evolution for atheism, not these other things.

I conclude that, if all that is to be said about Draper's argument is what Plantinga has to say about it, then-contrary to Plantinga's repeated claim throughout Where the Conflict Really Lies that there is no conflict between evolution and theism, where by "conflict" he means to include what he calls "probabilistic incompatibility" - evolution does constitute significant evidence against theism.

\section{SHOWING $\mathrm{P}(\sim \mathrm{S} / \mathrm{N})>$ ! $\mathrm{P}(\sim \mathrm{S} / \mathrm{T})$}

As I said, Draper sets out to establish that $\mathrm{P}(\mathrm{E} / \mathrm{N})>$ ! $\mathrm{P}(\mathrm{E} / \mathrm{T})$ by doing two things: (i) showing that $\mathrm{P}(\sim \mathrm{S} / \mathrm{N})>$ ! $\mathrm{P}(\sim \mathrm{S} / \mathrm{T})$ and (ii) showing that $\mathrm{P}(\mathrm{E} / \sim \mathrm{S} \& \mathrm{~N}) \geq \mathrm{P}(\mathrm{E} / \sim \mathrm{S} \& \mathrm{~T})$. I will focus on (i).

Draper's argument for $\mathrm{P}(\sim \mathrm{S} / \mathrm{N})>$ ! $\mathrm{P}(\sim \mathrm{S} / \mathrm{T})$ moves in two steps. Step 1 consists in an argument for the claim that $\mathrm{P}(\sim \mathrm{S} / \mathrm{N})>\mathrm{P}(\sim \mathrm{S} / \mathrm{T})$. Step 2 consists in an argument for the claim that " $\mathrm{P}(\sim \mathrm{S} / \mathrm{T}) \leq 1 / 2$, which is to say $\mathrm{P}(\mathrm{S} / \mathrm{T}) \geq 1 / 2$ - that, independent of the evidence for evolution, special creationism is at least twice as likely as not on the assumption that theism is true". In defense of this last claim, Draper rejects reasons for thinking that God did not specially create and affirms reasons for thinking that God did specially create, inferring that $\mathrm{P}(\mathrm{S} / \mathrm{T}) \geq 1 / 2$. If both steps are well-placed, it follows that $\mathrm{P}(\sim \mathrm{S} / \mathrm{N})>$ ! $\mathrm{P}(\sim \mathrm{S} / \mathrm{T})$.

I will focus on Step 1: $\mathrm{P}(\sim \mathrm{S} / \mathrm{N})>\mathrm{P}(\sim \mathrm{S} / \mathrm{T})$. That is to say: abstracting from the evidence for evolution, given our epistemic situation, we have better reason to believe the denial of special creationism on the assumption that naturalism is true than on the assumption that theism is true. And what is that reason, exactly? Here are Draper's words:

\footnotetext{
30 Ibid., 52.
} 
Since naturalism entails that no God exists, it entails that special creationism is false. Thus, the falsity of special creation is antecedently certain on naturalism: $\mathrm{P}(\sim \mathrm{S} / \mathrm{N})=$ 1. But on theism special creationism might, for all we know antecedently, be true: $\mathrm{P}(\sim \mathrm{S} / \mathrm{T})<1 .^{31}$

The argument here seems to be that, first of all, abstracting from our evidence for evolution, we have maximally good reason to believe the denial of special creationism given naturalism. However, secondly, abstracting from our evidence from evolution, for all we know, special creationism is true given theism, and so we do not have maximally good reason to believe the denial of special creationism given theism. Therefore, abstracting from the evidence for evolution, we have better reason to believe the denial of special creationism on the assumption that naturalism is true than on the assumption that theism is true.

The first thought — the thought that, abstracting from our evidence for evolution, we have maximally good reason to believe the denial of special creationism given naturalismseems to me to be right. That is because, by definition, naturalism entails the denial of special creationism. Therefore, we have just as good a reason to expect that special creationism is false given naturalism as we have to expect that Joe is unmarried given that Joe is a bachelor-which is to say we have maximally good reason to believe it, or as close to maximally good reason to believe it as to make no difference for our purposes.

The second thought, however- the thought that, abstracting from our evidence for evolution, for all we know, special creationism is true given theism, and so we do not have maximally good reason to believe the denial of special creationism given theism-does not seem clearly right. For it is not just obvious that, for all we know, special creationism is true given theism. Whether that's so depends on what we know. Of course, we can't say that, by definition, theism entails the denial of special creationism. But, even so, theism might yet entail the denial of special creationism. One proposition might non-trivially entail the denial of another without doing so by definition. We need, therefore, to consider arguments for the conclusion that $\mathrm{P}(\sim \mathrm{S} / \mathrm{T})=1$.

Now, one might think that this is a desperate maneuver. After all, on theism, God is omnipotent and omniscient, and so he would have the power and wisdom to create directly by way of intervention in the natural order. So, abstracting from the evidence for evolution,

${ }^{31}$ Draper 2008a [1997]: 210. 
this gives us at least some reason to expect God to specially create, and so we do not have maximally good reason to believe the denial of special creationism given theism.

This argument contains a non sequitur. For, even though, on theism, God would have the power and wisdom to create directly by way of intervention in the natural order, we might have maximally good reason to think that, as a matter of necessity, he would not exercise his power and wisdom toward that end. If that were the case, then, abstracting from the evidence for evolution, we would have maximally good reason to expect God not to specially create. So there is no avoiding the question: do we have any such reason? I know of only one candidate worth considering.

Leibniz famously argued that, contrary to Newton and his followers, according to whom God intervened occasionally to maintain the orbits of the planets, God would not need to intervene since, at creation, he would have sufficient wisdom and power to decree that the denizens of the natural world would possess those properties and powers necessary to achieve his purposes in creating them in the first place, without ever having to step in later to tinker here and there. "Whoever thinks otherwise must needs have a very mean notion of the wisdom and power of God". ${ }^{32}$ Leibniz's claim is relevant to our concerns. For if it is true, then, on the assumption that there is a God whose purposes call for life to come into existence and for complex organisms to exist, he would-right from the start, so to speakuse his power and wisdom to decree initial conditions, laws, and whatever else he deemed necessary to ensure that life arose in the natural order of things, in all its complexity and diversity, without any need for later intervention on his part to keep things "on track".

The point here is not just that God's purposes in creating complex living things would be better served by a law-governed world, and so without his fixing it now and again, although that is a point worth making. Indeed, there seem to be great goods that require nomic regularity, e.g. the mutual interdependence of living things, free and effective choice, genuine love relationships, and the satisfaction of intellectual investigation. Rather, the point is that if God were to achieve his purposes in creating living things by bestowing on them those properties and powers necessary to achieve his purposes, without his ever having to step in later and make adjustments-well, that would be a great good in itself, in addition to whatever other goods might be served by the arrangement. How might we think of this

${ }^{32}$ Leibniz 1956 [1715-1716]: 11-12. 
good? Wrapping up his discussion of Leibniz, Malebranche, and others on the matter, Michael Murray describes it like this:

[T] here is something grand, beautiful, and artful about a universe which contains within it everything that is necessary in order for it to bring about the results God intends for it. God could cause every event that we see in the natural world directly. But a powerful and rational designer would...display his power and reason far more manifestly in a universe which is itself a machine-making machine. A universe which achieves the ends God has for it in this self-contained fashion does as much to express the glory of its creator as do the end-products of the creative process. ${ }^{33}$

So a universe populated only with things whose properties and powers suffice to render it unnecessary for God to tinker with it later is a world that is maximally "grand, beautiful, and artful," manifesting the gloriousness of its creator, his power and his wisdom.

Let 'a Leibnizian natural world' designate a natural world populated only with things whose properties and powers suffice to render it unnecessary for God to tinker with them later in order to achieve his purposes. Now consider the following argument, call it the Leibnizian argument for $P(\sim S / T)=1$, or just the Leibnizian argument, for short.

1. Necessarily, if God exists, then, at creation, God has the power and wisdom to create a Leibnizian natural world.

2. Necessarily, if, at creation, God has the power and wisdom to create a Leibnizian natural world, then he will exercise his power and wisdom toward that end, provided that he has good enough reason to do so.

3. Necessarily, God has good enough reason to do so (if he exists).

4. So, necessarily, if God exists, then, at creation, he will exercise his power and wisdom to create a Leibnizian natural world.

Of course, as a matter of necessity, if God exercises his power and wisdom in this way, then that is how the natural world will be. Moreover, since what has just been said about a natural

\footnotetext{
33 Murray 2008: 146.
} 
world can with equal merit be said about any biological order that is a part of it, it follows from (4) that,

5. Necessarily, if God exists, then God will not specially create.

No doubt, Leibniz would concur: "Whoever thinks otherwise must needs have a very mean notion of the wisdom and power of God".

The proponent of the Leibnizian argument will regard it as maximally good reason for her to expect that God will not specially create given that theism is true. That is to say, she will infer that, relative to her and her own epistemic situation, $\mathrm{P}(\sim \mathrm{S} / \mathrm{T})=1$. She will also point out that, as an added bonus, her expectation that God will not specially create is somewhat confirmed-or at least not as yet disconfirmed-by observed regularities in nature as well as the success of the physical sciences in offering purely naturalistic explanations for the many processes and events in the natural order it has come to understand, all independent of the evidence for evolution. ${ }^{34}$

Draper considers something along these lines, specifically an argument that he finds in the writings of Diogenes Allen and Howard J. Van Till, but he says he doesn't find it at all convincing. He writes:

Perhaps the idea is that, just as a perfectly rational car manufacturer would produce a car that never needed its gas tank filled or its air filter replaced, a perfectly rational creator would make a universe that ran on its own. But such a car would be preferable because filling up with gas or replacing parts has a cost in terms of time, energy, and so on. An omnipotent and omniscient creator wouldn't have such worries. In general, what counts as a rational or perfect or defective universe depends on the creator's goals. What goal or plan of God would be better served by a universe in which God never intervened? $?^{35}$

Whether these words suffice to dispose of Allen and Van Till's argument need not concern us, for they do nothing to tarnish the Leibnizian argument. The goal of God that would be

${ }^{34}$ For more on the Leibnizian conception of God's natural providence, see Murray 2003 and 2008.

${ }^{35}$ Draper 2008a [1997]: 211. 
better served by a natural world in which he never intervened is, in Murray's words, a world that is maximally "grand, beautiful, and artful," one that better manifests God's power and wisdom in achieving the other ends for the sake of which he created it. Notice also that such ends as those mentioned earlier - the mutual interdependence of living things, free and effective choice, genuine love relationships, the satisfaction of intellectual investigationwould be ensured by a Leibnizian natural world.

I anticipate the following objection to the Leibnizian argument. "Although we are well-situated to tell whether premises (1) and (2) are true and we are well-situated to discern the argument's validity, we are in no position to tell whether premise (3) is true. After all, what if there is some greater good that would be realized if God were to intervene directly in the natural order and brought about his purposes in creation by occasionally tinkering with the properties and powers of some of the inhabitants of the natural world? It seems that, necessarily, God has good enough reason to exercise his power and wisdom to create a Leibnizian natural world only if it is absolutely impossible for there to be such a greater good. But we are in no position to say that it is absolutely impossible for there to be such a greater good. So we are in no position to say whether, necessarily, God has good enough reason to exercise his power and wisdom to create a Leibnizian natural world. That is, we are in no position to say whether premise (3) is true. Therefore, given our epistemic situation, the Leibnizian argument is not a maximally good reason for anyone-including its proponentto believe the denial of special creationism given theism. Absent any other consideration, we must conclude that $\mathrm{P}(\sim \mathrm{S} / \mathrm{T})<1$."

By way of reply, I agree with everything up to the 'Therefore'. At that point, however, the objection goes sour. For, even though we are in no position to say whether premise (3) is true, it does not follow that, given our epistemic situation, the Leibnizian argument is not a maximally good reason for us to believe the denial of special creationism given theism. The most that we can infer from the fact that we are in no position to say whether or not premise (3) is true is that we are in no position to say whether, given our epistemic situation, the Leibnizian argument is a maximally good reason for us to believe its conclusion. That is, the most that we can infer is that we are in no position to say whether $\mathrm{P}(\sim \mathrm{S} / \mathrm{T})=1$. Let me explain.

My explanation will be from my own point of view. During the course of my explanation, I will dispense with the fiction that we share a common epistemic situation that 
renders it appropriate for me to say things like "we are in no position to say whether or not (3) is true" and "we are in no position to say whether, given our epistemic situation, the Leibnizian argument is a maximally good reason for us to believe its conclusion" and so on. I can't speak for you. You'll have to speak for yourself.

So consider the following proposition:

- I have maximally good reason to believe the conclusion of the Leibnizian argument, given my epistemic situation.

Is it true? Well, what is my "epistemic situation"? Here are some salient items: my understanding and awareness of the premises and inferences that constitute the Leibnizian argument, my judgment that the inferences are valid, my judgment that premises (1) and (2) are true, my judgment that premise (3) is the only questionable thing about the argument, my judgment that I am in no position to tell whether or not (3) is true, my belief that, for any noncircular sound argument, it is a maximally good reason for me to believe its conclusion, and my judgment that, aside from premise (3), the Leibnizian argument is a noncircular sound argument for its conclusion. In light of the fact that my epistemic situation includes these items, is the proposition indented just above true? Is it true that $I$ have maximally good reason to believe the conclusion of the Leibnizian argument, given my epistemic situation?

I can't tell.

That's not because I can't tell whether I have the Leibnizian argument. Of course I have it. As I said, I understand each of the statements that constitute it, and I'm aware of each of its premises and inferences. Moreover, I wrote it out a couple of pages back, and I'm staring at it on a page next to me, and I have several electronic copies of it in my two computers. So I have it. Rather, I can't tell whether it is a maximally good reason for me to believe its conclusion because my epistemic situation puts me in no position to say whether it is such reason. For all I can tell, it is; then again, for all I can tell, it isn't. I am in the dark about the matter. I am in the dark about whether $\mathrm{P}(\sim \mathrm{S} / \mathrm{T})=1$.

Perhaps one will object. "We're talking here about reasons for one to believe something, given one's epistemic situation. In general, if one of the premises of an argument is inscrutable to a person, then, given her epistemic situation, how can it provide her with a good reason, much less a maximally good reason, to believe its conclusion? It can't. And the 
same goes for you and your epistemic situation vis-à-vis the Leibnizian argument. Given how you have described your epistemic situation-and, more specifically, given the inscrutability of premise (3) to you - the Leibnizian argument does not give you a maximally good reason to believe its conclusion".

By way of reply, I never said that the Leibnizian argument gave me or provided me with a maximally good reason to believe its conclusion. Rather, I said that I have it and that my epistemic situation does not permit me to tell whether it is a maximally good reason for me to believe its conclusion. Of course, if the Leibnizian argument did give or provide me with a reason to believe its conclusion, then I'd be rational, justified, warranted, or otherwise epistemically up to snuff in believing its conclusion on the basis of it. But I'm not. So it neither gives nor provides me with any such thing. My conceding that point, however, is right at home with my being in the dark about whether it is a maximally good reason for me to believe its conclusion.

The objector might persist. "Wouldn't the Leibnizian argument be much better if you were able to tell whether premise (3) is true? Of course it would. But if it would be better, then it's not maximally good. Therefore, the Leibnizian argument is not a maximally good reason for you to believe its conclusion".

I disagree. To suppose that it-the Leibnizian argument-would be better if I was able to tell whether premise (3) is true is like supposing that Mt. Adams basking in a late August alpenglow would be more beautiful if Trevor Thomas had been able to see it when he walked its western flank in 2010. ${ }^{36}$ It is like supposing that an instance of modus ponens would be improved if your student who can't distinguish it from the fallacy of affirming the consequent gained the ability to do so. The goodness of an argument is not the least bit affected by the deficiencies of those who entertain it, or the removal of those deficiencies.

The objector might persist some more. "Look. Even if it is not the case that the Leibnizian argument would be better if you were able to tell whether premise (3) is true, it is not a maximally good reason for you to believe its conclusion. That's because, in general, an argument is a good reason for someone to believe its conclusion only if she is in a position to discern the truth of all of its premises. But, as you admit, you are in no such position with respect to premise (3) of the Leibnizian argument. Thus, it is not a good reason for you to believe its conclusion, given that your description of your epistemic situation is accurate. $A$

\footnotetext{
${ }^{36}$ See http://www.blindhikertrevorthomas.com/
} 
fortiori, given your epistemic situation, it is not a maximally good reason for you to believe its conclusion".

Once again, I disagree. I doubt that, "in general, an argument is a good reason for someone to believe its conclusion only if she is in a position to discern the truth of all of its premises". Whether an argument is a good reason for someone to believe its conclusion has nothing at all to do with her. Rather, it has to do with it: with whether the premises are true, with whether they adequately support its conclusion, and the like. If an argument has goodmaking features such as these, features that do not have anything to do with us, then it is a good reason for us to believe its conclusion-even if some limitation of ours hinders us from discerning those features. In the same way, Mt. Adams basking in a late August alpenglow is a beautiful sight for Trevor Thomas to see even though he is blind. Likewise, the conditional corresponding to modus ponens is a good thing for your student to understand even if she lacks the capacity to do so.

There are other objections along these lines that we might consider. But, so far as I can see, they all fail to take into account what it is for an argument to be a good reason for us to believe its conclusion. The bottom line is that, given our epistemic situation, we can be in the dark about whether some argument is a good reason for us to believe its conclusion. That's how it is for us and the Leibnizian argument; or, at any rate, that's how it is for me. (That is also how it is for me and the best versions of the ontological argument, where everything rests on the possibility premise, which-like premise (3) of the Leibnizian argument-I am in no position to tell whether it is true or false.)

Earlier, I mentioned Draper's argument for thinking that it is false that $\mathrm{P}(\sim \mathrm{S} / \mathrm{T})=1$. It went like this: abstracting from our evidence for evolution, for all we know, special creationism is true given theism, and so we do not have maximally good reason to believe the denial of special creationism given theism. I remarked that it is not just obvious that, for all we know, special creationism is true given theism. Whether that's so depends on what we know. I then turned to the Leibnizian argument. As I have indicated, however, that argument leaves intact Draper's premise that, abstracting from our evidence for evolution, for all we know, special creationism is true given theism. So what should we make of Draper's argument? I think we should reject the inference. For, even if it is true that, abstracting from our evidence for evolution, for all we know, God might specially create, we might yet possess, unbeknownst to us, a maximally good reason for us to believe that he 
wouldn't. That's what our position vis-à-vis the Leibnizian argument demonstrates; or, more accurately, that's what my position vis-à-vis that argument demonstrates.

To recapitulate, and to revert to the fiction that we share the same epistemic situation: if we are in no position to tell whether, given our epistemic situation, the Leibnizian argument is a maximally good reason for us to expect the denial of special creationism given theism, then we are in no position to tell whether, given our epistemic situation, our reason to expect the denial of special creationism given naturalism is better than our reason to expect the denial of special creationism given theism. That is, we are in no position to tell whether $\mathrm{P}(\sim \mathrm{S} / \mathrm{N})>\mathrm{P}(\sim \mathrm{S} / \mathrm{T})$, which is the conclusion of Step 1 - unless, of course, we have something else to settle the matter.

Draper seems to think we do have something else to settle the matter. At any rate, he offers an argument that, by his lights, constitutes "very strong antecedent reason for believing that God did create at least some complex life independently," given that theism is true. ${ }^{37}$ Let's take a look at this "very strong reason". Here it is in his own words:

Theism implies an extreme metaphysical dualism - a mind existed prior to the physical world and was responsible for its existence. Thus on the assumption that theism is true, it is antecedently [epistemically] likely that minds are fundamentally nonphysical entities and hence that conscious life is fundamentally different from nonconscious life. But this in turn makes it [epistemically] likely that conscious living things are not just the genetically modified descendents of nonconscious living things - that conscious life was created independently. And since special creationism is defined as the position that at least some complex life was created independently, it follows that, on the assumption that theism is true, it is antecedently [epistemically] likely that special creationism is true.

The dualism inherent in theism may explain why so many theists were drawn to the idea of special creationism before (and in many cases after) the evidence for evolution was discovered. For this dualism supports a dualistic view of human nature-a view that must have made the idea that we are the effect of altering the nucleic acids of single-celled organisms seem ludicrous. Offspring don't have to be identical that their parents, but surely genetic change can't result in fundamental

\footnotetext{
${ }^{37}$ Draper 2008a [1997]: 212.
} 
metaphysical lines being crossed! Thus, even if we know by past experience that God, assuming he exists, generally doesn't intervene in nature, the sort of metaphysics presupposed by theism makes it antecedently [epistemically] likely that God did intervene in the physical world in order to create a mental world within it. So it's hardly surprising that, before Darwin, many theists were special creationists. ${ }^{38}$

I think that we can fairly reconstruct the argument of this passage as follows:

1. Necessarily, if theism is true, then an immaterial mind existed prior to the physical world and is responsible for its existence.

2. So, abstracting from the evidence for evolution, we have very good reason to expect that, given theism, minds are fundamentally immaterial. (from 1)

3. Necessarily, if minds are fundamentally immaterial, then conscious living things are fundamentally different from nonconscious living things.

4. So, abstracting from the evidence for evolution, we have very good reason to expect that, given theism, nonconscious living things are fundamentally different from conscious living things. (from 2 and 3)

5. Necessarily, if nonconscious living things are fundamentally different from conscious living things, then conscious living things are not just the genetically modified descendents of nonconscious living things but rather were created independently by God.

6. Necessarily, if conscious living things are not just the genetically modified descendents of nonconscious living things but rather were created by God independently, then special creationism is true.

7. So, abstracting from the evidence for evolution, we have very good reason to expect that, given theism, special creationism is true. (from 4-6)

What should we make of this line of thought?

Well, premises (1) and (6) are true by definition, and (4) and (7) seem to follow from the indicated premises. That leaves (2), (3), and (5). Two ideas are lurking in these three premises, the idea of something of one sort being "fundamentally" of another sort and the

38 Ibid., 212. 
idea of something of one sort being "fundamentally different" from something of another sort. Draper does not expound on these ideas, so we cannot be sure what he means by these premises. Nevertheless, what he has in mind seems clear enough.

Draper seems to have in mind two principles. The first principle is that

- for some pairs of categories, F and G, the Fs are fundamentally Gs just in the case that, necessarily, if something is an F, then it is a G;

that is, nothing can be an F unless it is a G. Dogs are, in this sense, fundamentally animals; nothing can be a dog unless it's an animal. Numbers, in this sense, are fundamentally immaterial; nothing can be a number unless it's immaterial. The second principle is that, for some pairs of categories, F and G, the Fs are fundamentally different from the Gs just in the case that it is absolutely impossible for there to be a series of modifications of something that is an F such that, by virtue of the cumulative effect of that series of modifications alone, something that is a $G$ comes to be. And the modifications in the series can be as gradual as you like and take as much time as you like and involve as many things as you like. For the sake of brevity, let's stipulate that the necessary and sufficient condition just lain down for the Fs being fundamentally different from the Gs holds between the Fs and the Gs if and only if nothing can bridge the gap between them. This seems to be in the spirit of what Draper says when he speaks of "fundamental metaphysical lines" that "can't be crossed," only I prefer the metaphor of a metaphysical gap to that of a metaphysical line. Thus, the second principle can be put more succinctly as follows:

- for some pairs of categories, F and $G$, the Fs are fundamentally different from the Gs just in the case that nothing can bridge the gap between the Fs and the Gs.

Perhaps the categories of abstracta and concreta are uncontroversial instances of this principle.

With all this in hand, we can see that premise (5) of Draper's argument is true. It is necessary that, if nothing can bridge the gap between nonconscious living things and conscious living things, then a series of genetic modifications can't bridge the gap either. But 
is it true that nothing can bridge the gap between nonconscious living things and conscious living things?

Draper seems to think so-at least if nothing can be a mind unless it is immaterial. That's just his premise (3), which, given the second of the two principles I have imputed to him, is to be understood as this:

3'. Necessarily, if nothing can be a mind unless it is immaterial, then nothing can bridge the gap between nonconscious living things and conscious living things.

What should we make of (3')?

I think it is false. For even if nothing can be a mind unless it is immaterial, some things bridge the gap between nonconscious living things and conscious living things. For example, some living things are awake and then sleep soundly, after which time they wake up; and some living things get knocked out, after which time they regain consciousness. In these cases, there is a nonconscious living thing and there is series of modifications of itthe soundly sleeping or knocked-out organism—such that, by virtue of the cumulative effect of that series of modifications alone, a conscious living thing comes to be. And this can be the case even on the assumption that nothing can be a mind unless it is immaterial.

Perhaps Draper didn't mean (3') by (3). Perhaps he meant

3". Necessarily, if nothing can be a mind unless it is immaterial, then nothing can bridge the gap between living things that lack the capacity for consciousness and living things that possess the capacity for consciousness.

(3") avoids the counterexamples posed by sound sleepers and the knocked-out. Unfortunately, however, it is false. For even if nothing can be a mind unless it is immaterial, some living things that lack the capacity for consciousness naturally develop in such a way that they come to possess that capacity. You, for example, are a good illustration of this fact. That's because you are an animal and, as such, you were once a fetus that lacked the capacity for consciousness. True enough, at that time, you had the capacity to develop into something that has the capacity for consciousness. But we must not confuse the capacity to 
develop into something that has the capacity for thus-and-so with the capacity for thus-andso.

Now I grant that the claim that you are an animal is contentious, perhaps even offensive. But the same point could be made with respect to some livings things whose status as animals is indisputable, for example, the Olympic marmot. ${ }^{39}$ For any Olympic marmot pup that survives until it emerges from its birth burrow (typically, at about fourteen weeks after conception), there was a time when it was a fetus and lacked the capacity for consciousness. That time was followed by a series of modifications of that fetus such that, by virtue of the cumulative effect of that series of modifications alone, something that possessed the capacity for consciousness came to be. Gap bridged.

Perhaps Draper did not mean (3”) by (3). Perhaps he meant

3"'. Necessarily, if nothing can be a mind unless it is immaterial, then nothing can bridge the gap between one species of living thing whose members lack any capacity for consciousness and another species of living thing whose members tend to possess a capacity for consciousness.

(3"') avoids the counterexamples that demonstrate the falsity of ( 3 ') and (3"); moreover, it is not susceptible to easy counterexample in the way the latter are, so far as I can see.

Nevertheless, worries stemming from the doctrine of the essentiality of origins aside, ${ }^{40} \mathrm{I}$ do not see why it is not possible for an Olympic marmot to be a product of a series of modifications of a large enough puddle of aerobacter aerogenes. Of course, we are presently incapable of creating any such series ourselves; but since, at bottom, the specialized cells, tissues, and organs of a marmot are nothing but elementary particles arranged in a certain fashion, while undergoing the processes that unify them and what they constitute into a marmot life, I don't see why there could not be a series of modifications of a puddle of aerobacter aerogenes the end result of which was a marmot, or at least a marmot-like living thing. ${ }^{41}$

\footnotetext{
${ }^{39}$ See http://en.wikipedia.org/wiki/Olympic marmot.

${ }^{40}$ See Kripke 1972: 114n56, for an argument for the doctrine. For critical discussion, see Cameron 2005.

41 There appears to be progress, however. See Pennisi 2010, Venter 2010, and the publications at http://www.jcvi.org/cms/research/projects/first-self-replicating-synthetic-bacterial-cell/publications/.
} 
But whether I'm right about that or not, the deepest difficulty with Draper's argument for believing that, on the assumption that theism is true, God directly created at least some complex life, is not premise (3) but premise (2). Given the first principle above that I imputed to Draper, premise (2) reads as follows:

2'. So, abstracting from the evidence for evolution, we have good reason to expect that, given theism, nothing can be a mind unless it is immaterial.

What should we make of (2')?

Naturally, we will agree that, given Draper's definition of "theism," it is necessary that, if theism is true, then an immaterial mind existed prior to the physical world and is responsible for its existence. That's what premise (1) states. And Draper explicitly infers (2) from (1): that's what the word "Thus" indicates in the passage quoted at length above. But, how does (1) even begin to suggest that (2') is true? How does the fact that, necessarily, if theism is true, then an immaterial mind existed prior to the physical world and is responsible for its existence, even begin to suggest that, abstracting from the evidence for evolution, we have good reason to expect that, given theism, nothing can be a mind unless it is immaterial?

Suppose we grant that minds are things that are capable of consciousness-including a subjective point of view, as Thomas Nagel never tires of reminding us - and that they are capable of rationality, intention, and action. In that sense of the word "mind," you and I are both minds, as is God (if God exists). Furthermore, let us suppose that God exists and that, therefore, at least one mind is immaterial. Okay. So far so good. Should we infer that, therefore, abstracting from the evidence for evolution, all minds-including ourselves — are immaterial? Is that the inference Draper wishes us to draw?

Of course, we're all familiar with arguments for the conclusion that nothing could be a mind unless it is immaterial; and we're all equally familiar with arguments for the conclusion that we are merely material beings. But if Draper meant to take a stand on this debate, he would have mentioned it. No, I rather think that the suggestion he means to put forward-and I see no hermeneutical option here-is that if an immaterial mind shows up in the first scene of the first act of the only play on the ontological stage, then that fact all by itself gives us "very good reason" to expect that material minds will not show up in any scene of any act in that play. 
How are we to make sense of this inference?

Perhaps it's an inference by analogy. In the Game of the Nature of Mind, the opponents are those who think that human minds are material and those who think that minds in general, including human minds, are immaterial: the materialists against the immaterialists. If we go into the game spotting the immaterialists a divine mind, then the score is 1-0 in favor of the immaterialists before the materialists even go to bat. Of course, as everyone knows, $68.9 \%$ of the time, baseball teams that score first win the game. Thus, by analogy, we have good reason to believe that the immaterialist will win. That is, we have good reason to believe that, abstracting from the evidence for evolution, all mindsincluding human minds_-are immaterial, given theism. Is that Draper's "very good reason"?

Of course, I jest. But I do not jest without a point. I find it enormously difficult to see how it can be that the mere existence of an immaterial mind that existed prior to the physical world and that is responsible for its existence constitutes any reason at all to suppose that, abstracting from the evidence for evolution, nothing can be a mind unless it is immaterial. And so I not only have the difficulty of accepting premise (3), I have the difficulty of accepting premise (2) as well.

\section{CONCLUSION}

To establish premise (2) of his evolutionary argument for atheism, Draper set out to do two things: show that $\mathrm{P}(\sim \mathrm{S} / \mathrm{N})>! \mathrm{P}(\sim \mathrm{S} / \mathrm{T})$ and show that $\mathrm{P}(\mathrm{E} / \sim \mathrm{S} \& \mathrm{~N}) \geq \mathrm{P}(\mathrm{E} / \sim \mathrm{S} \& \mathrm{~T})$. Draper's argument for $\mathrm{P}(\sim \mathrm{S} / \mathrm{N})>$ ! $\mathrm{P}(\sim \mathrm{S} / \mathrm{T})$ included the claim that $\mathrm{P}(\sim \mathrm{S} / \mathrm{N})>\mathrm{P}(\sim \mathrm{S} / \mathrm{T})$. While we rightly agree that $\mathrm{P}(\sim \mathrm{S} / \mathrm{N})=1$, Draper has not established that $\mathrm{P}(\sim \mathrm{S} / \mathrm{T})<1$. Indeed, by my lights, given the Leibnizian argument, we are in no position to say whether $\mathrm{P}(\sim \mathrm{S} / \mathrm{T})=1$, absent any further consideration. What further consideration Draper has to offer, however, is a failure, in my opinion. So far as I can see, therefore, Draper's evolutionary argument for atheism is not good reason for us to think that evolution provides significant evidence for atheism.

Of course, I may have interpreted Draper's argument incorrectly. Thus, I grant that what he in fact said, unlike what I understood him to say, might well constitute good reason for us to think that evolution provides significant evidence for atheism. And, of course, even 
if I have understood and assessed his argument correctly, evolution might yet provide significant evidence against theism. But if it does, then, if I have understood and assessed Draper's argument correctly, we need to look elsewhere to see how evolution provides significant evidence-or any evidence at all—for atheism. ${ }^{42}$

\section{REFERENCES}

Cameron, R. (2005), 'A Note on Kripke's Foonote 56 Argument for the Essentiality of Origins', in Ratio 18: 262-275.

Chomsky, N. (2005), 'Three Factors in Language Design', in Linguistic Inquiry 36: 1-22.

Diamond, J. (1992), The Third Chimpanzee (New York: Harper \& Row).

Draper, P. (1989), 'Pain and Pleasure: An Evidential Problem for Theists', in Nous 23: 331-350. Reprinted in D. Howard-Snyder (ed.), The Evidential Argument from Evil (Bloomington, IN: Indiana University Press) (1996): 12-29.

Draper, P. (2008a [1997]), 'Evolution and the Problem of Evil', in L. Pojman and M. Rea (eds.), Philosophy of Religion: An Anthology, $5^{\text {th }}$ edition (CA: Wadsworth): 207-219. (Originally published in 1997.)

Draper, P. (2008b), 'The Argument from Evil', in Philosophy of Religion: Classic and Contemporary Issues, eds. Paul Copan and Chad Meister (Oxford: Blackwell Publishing): 142-155.

Draper, P. and Doughtrey, T. (2013), 'Explanation and the Problem of Evil', in J. McBrayer and D. Howard-Snyder (eds.), The Blackwell Companion to the Problem of Evil (Malden, MA: Wiley Blackwell): 67-82.

Hájek, A. (2012), 'Interpretations of Probability', The Stanford Encyclopedia of Philosophy (Winter 2012 Edition), E.N. Zalta (ed.), URL = <http://plato.stanford.edu/archives/win2012/entries/probability-interpret/>.

Kretzmann, N. (1998), The Metaphysics of Creation: Aquinas's Natural Theology in Summa Contra Gentiles II (New York: Oxford University Press).

Kripke, S. (1972), Naming and Necessity (Cambridge, MA: Harvard University Press).

Leibniz, G.W. (1956 [1715-1716]), in H.G. Alexander (ed.), The Leibniz-Clarke Correspondence, (Manchester: Manchester University Press).

Mcbrearty, S., and Brooks, A. (2000), 'The Revolution that Wasn't: a New Interpretation of the Origin of Modern Human Behavior', in Journal of Human Evolution 39: 453-463.

Murray, M. (2003), 'Natural Providence (or Design Trouble)', in Faith and Philosophy 20: 307327.

Murray, M. (2008), Nature Red in Tooth and Claw: Theism and the Problem of Animal Suffering (New York: Oxford University Press).

Papineau, D. (2009), 'Naturalism', in The Stanford Encyclopedia of Philosophy, E.N. Zalta (ed.), $\mathrm{URL}=<$ http://plato.stanford.edu/archives/spr2009/entries/naturalism/>.

Pennisi, E. (2010), 'Synthetic Genome Appears to Bring New Life to Bacterium', in Science: 958-59; http://www.sciencemag.org/content/328/5981/958.full.pdf.

Plantinga, A. (2011), Where the Conflict Really Lies: Science, Religion, and Naturalism (New York: Oxford University Press).

${ }^{42}$ For comments on earlier drafts, I thank Frances Howard-Snyder, Hud Hudson, John A. Keller, and Dennis Whitcomb. 
Van Inwagen, P. (1997), 'Probability and Evil', in The Possibility of Resurrection and Other Essays in Christian Apologetics (Boulder, CO: Westview Press).

Van Inwagen, P. (2010), 'A Kind of Darwinism', 'Darwinism and Design', 'Science and Scripture', in M, Stewart (ed.), Science and Religion in Dialogue, Volume 2 (Malden, MA: Wiley Blackwell): 813-846.

Venter, J.C., et al. (2010), 'Creation of a Bacterial Cell Controlled by a Chemically Synthesized Genome', in Science: 52-56; http://www.sciencemag.org/content/329/5987/52.full. 